\title{
Nutrient availability in the rhizosphere of rice grown with plastic film mulch and drip irrigation
}

\author{
Q.C. Zhu, C.Z Wei*, M.N. Li, J.L. Zhu, J. Wang \\ Key Laboratory of Oasis Eco-Agriculture, College of Agriculture, Shihezi University, Shihezi, People's Republic of China 832003 \\ *Corresponding author: changzhouwei@126.com
}

\begin{abstract}
The combined use of plastic film mulch and drip irrigation for rice production could result in high yields and significant water savings. However, little is known about soil nutrient availability in this system. The objective of this laboratory experiment was to measure the availability of soil N, P, K, Zn, and $\mathrm{Mn}$ in two treatments: (i) conventional flood irrigation (FI) and (ii) plastic film mulch and drip irrigation (PFM-DI). Rice (Oryza sativa L. cv T-04) was sown in plastic boxes containing $80 \mathrm{~kg}$ soil. Bulk and rhizosphere soil samples were collected at four growth stages (i.e., tillering, jointing, full heading, and grain filling). Soil NH4-N and exchangeable Mn concentrations were lower in the PFM-DI treatment than in the FI treatment. In contrast, concentrations of $\mathrm{NO}_{3}-\mathrm{N}$, available $\mathrm{K}$, available Zn, and easily reduced Mn were higher in the PFM-DI treatment than in the FI treatment. There was no significant difference in Olsen P between FI and PFM-DI treatments. Soil $\mathrm{NH}_{4}-\mathrm{N}$, available $\mathrm{K}$ and exchangeable $\mathrm{Mn}$ concentrations were lower in rhizosphere soil than in bulk soil. In contrast, $\mathrm{NO}_{3}-\mathrm{N}$ and $\mathrm{Zn}$ concentrations were higher in rhizosphere soil than in bulk soil. Neither available P nor easily reduced $\mathrm{Mn}$ concentrations differed between rhizosphere and bulk soil. Our results indicated that compared with conventional flood irrigation, the plastic film mulch plus drip irrigation system increased soil nutrient availability.
\end{abstract}

Keywords: Nutrient availability, rice, plastic film mulch and drip irrigation, flood irrigation, rhizosphere, bulk soil

Abbreviations: FI - conventional flood irrigation, PFM-DI - plastic film mulch and drip irrigation. 


\section{Introduction}

The combined use of plastic film mulch and drip irrigation (PFM-DI) is an important water-saving technology. Yields as high as $12045 \mathrm{~kg} \mathrm{hm}^{-2}$ were reported for rice grown with PFM-DI at the Xinjiang Tianye Agriculture Research Institute in China (Guo and Chen 2012). The PFM-DI treatment also reduced water use by $60 \%$ compared with conventional flood irrigation (FI).

The soil environment in drip-irrigated fields is very different than that in either flood irrigated or dryland fields. Drip-irrigation is the slow and frequent application of small amounts of water. For rice production with PFM- DI, the soil water content is maintained at $>90 \%$ of field capacity but never flooded. In contrast, in flood irrigated fields, the soil surface is completely covered by a shallow layer of water and the soil profile is continuously saturated (anaerobic). Soil water contents in dryland fields vary widely, depending on precipitation.

Soil water content and redox potential can directly or indirectly influence nutrient availability (Ciarlo et al. 2007; Martínez-Alcalá et al. 2009; Yoneyama et al. 2001). The change from FI to PFM-DI practices could cause dramatic changes in soil nutrient availability, especially the availability of metallic ions. This could affect rice growth and productivity. Little is known about the availability of nutrients to rice grown with PFM-DI. The objectives of this experiment were (i) to quantify soil nutrient availability under FI and PFMDI practices and (ii) to compare nutrient availability in bulk soil with that in rhizosphere soil. The results of this paper provide not only important insight about the effects of PFM-DI practices on nutrient availability but also a basis for fertilizing rice grown with PFM-DI.

\section{Materials and Methods}

\subsection{Soil properties}

This study was conducted at the Shihezi University
Agricultural Experiment Station, Shihezi City, Xinjiang Uyghur Autonomous Region, China $\left(44^{\circ} 18^{\prime} \mathrm{N}, 86^{\circ} 02^{\prime} \mathrm{E}\right)$ in 2012 . The soil in this study was collected from the $0-40 \mathrm{~cm}$ depth of paddy soil at the Taoyuan Farm, which is about $20 \mathrm{~km}$ from the experiment station. Rice had been grown on the soil for seven consecutive seasons. The soil texture was sandy loam. Some additional properties of the soil were as follows: $7.25 \mathrm{pH}, 5.00 \mathrm{~g} \mathrm{~kg}^{-1}$ organic matter, $37.8 \mathrm{mg} \cdot \mathrm{kg}^{-1}$ alkaline hydrolysis $\mathrm{N}, 4.60 \mathrm{mg} \mathrm{kg}{ }^{-1}$ Olsen-P, $137 \mathrm{mg} \mathrm{kg}^{-1}$ exchangeable $\mathrm{K}$ and $252 \mu \mathrm{sm}^{-1}$ electronic conductivity.

\subsection{Experimental design}

The paddy soil samples were air-dried, passed through a $4 \mathrm{~mm}$ sieve, and then added to plastic boxes $(60 \mathrm{~cm}$ $\times 45 \mathrm{~cm} \times 35 \mathrm{~cm})$. Each box contained $80 \mathrm{~kg}$ soil. Four boxes were used to simulate conditions in flooded paddy soils. These boxes had one to three drainage holes in their bottoms to simulate natural seepage at the rate of 3-6 $\mathrm{mm} \mathrm{d}^{-1}$. Four boxes with no holes in the bottoms were prepared to simulate conditions under drip irrigation. The soil surface in these four boxes was covered with transparent plastic polyethylene film (7 $\mu \mathrm{m}$ thick).

Root bags (300 mesh nylon net) were also filled with the paddy soil. The bags were $10 \mathrm{~cm}$ wide and either 5 , 8,10 , or $12 \mathrm{~cm}$ long. The soil in the bags was moistened and then 15 rice (Oryza sativa L. cv T-04) seeds were sown in each bag. Preliminary study indicated that this lowland rice cultivar was well adapted to the PFM-DI system. The bags were buried at the soil surface in the plastic containers described above and arranged so that there were three rows per container with eight bags (hills) per row. After emergence, the rice plants were thinned so that there were eight plants per bag.

The soil surface in the FI treatment was covered with a $3-5 \mathrm{~cm}$ deep layer of water throughout the experiment. In the PFM-DI treatment, water was added to the soil 
using an intravenous drip apparatus. The water content in the PFM-treatment was always $>90 \%$ of the soil water holding capacity; however, the soil was never allowed to reach saturation. Fertilizer was applied to all plots at the following rates: $0.2 \mathrm{~g} \mathrm{~N} \mathrm{~kg}^{-1}$ soil as urea, $0.2 \mathrm{~g} \mathrm{P}_{2} \mathrm{O}_{5}$ $\mathrm{kg}^{-1}$ soil as triple superphosphate, and $0.15 \mathrm{~g} \mathrm{~K}_{2} \mathrm{O} \mathrm{kg}$ soil as potassium sulfate. The $\mathrm{N}$ fertilizer was applied in five parts: $15 \%$ at planting, $30 \%$ at tillering, $40 \%$ at jointing-booting, and the remaining $15 \%$ at the panicle stage. The $\mathrm{P}$ and $\mathrm{K}$ fertilizers were applied at planting.

\subsection{Soil sampling}

Plant and soil samples were collected at tillering (4 July), jointing (29 July), full heading (24 August) and grain filling (7 September). The hills with the smallest root bags (i.e. $5 \mathrm{~cm}$ long) were harvested at tillering. The hills with the largest root bags (i.e., $12 \mathrm{~cm}$ long) were harvested at grain filling. On each sample date, the root-bags were carefully removed from the soil and then immediately placed in an ice-box. Soil samples were also collected about 4-5 $\mathrm{cm}$ away from where the root bag had been pulled out. The soil samples were taken to the laboratory and the roots were picked out of the root bags as soon as possible. The soil inside the bags was considered rhizosphere soil, whereas the soil collected outside the bags was considered bulk soil.

\subsection{Chemical analyses}

The soil samples were analyzed immediately after collection to prevent changes in nutrient availability because of drying (Wang et al. 2002). Soil samples were shaken in $2 \mathrm{M} \mathrm{KCl}$ (10:1 extractant:soil ratio) for $1 \mathrm{~h}$. Ammonium-N concentrations in the extracts were determined using the copperized cadmium reduction method (Dorich and Nelson 1984). Nitrate-N concentrations were determined using indophenol blue colorimetry (Dorich and Nelson 1983). Olsen P was extracted with $0.5 \mathrm{M} \mathrm{NaHCO}_{3}(\mathrm{pH}=8.5)$ using a 20:1 extractant:soil ratio for $0.5 \mathrm{~h}$. The $\mathrm{P}$ concentration in the extracts was determined by Mo-Sb colorimetry (Watanabe and Olsen 1965). Available K was extracted with $1 \mathrm{M} \mathrm{NH}_{4} \mathrm{OAc}(\mathrm{pH}=7)$ using a 10:1 extractant:soil ratio for $0.5 \mathrm{~h}$. The $\mathrm{K}$ concentration in the extracts was determined by flame photometry (Oliveira et al. 1971). Available $\mathrm{Zn}$ was extracted with $0.005 \mathrm{M}$ DTPA-TEA $(\mathrm{pH}=7.3)$ using a 2:1 extractant:soil ratio for $2 \mathrm{~h}$ at 25 ${ }^{\circ} \mathrm{C}$ (Lindsay and Norvell 1978). Exchangeable Mn and easily reducible $\mathrm{Mn}$ were sequentially extracted with $1 \mathrm{M} \mathrm{NH}_{4} \mathrm{OAc}(\mathrm{pH}=7.0)$ and $1 \mathrm{M} \mathrm{NH}_{4} \mathrm{OAc}+2 \mathrm{~g} \mathrm{~L}^{-1}$ hydroquinone $(\mathrm{pH}=7.0)$, using a 10:1 extractant:soil ratio. The samples were shaken for $0.5 \mathrm{~h}$ and then left to equilibrate for $6 \mathrm{~h}$ (Moraghan 1979). Available $\mathrm{Zn}$, exchangeable $\mathrm{Mn}$, and easily reducible $\mathrm{Mn}$ concentrations in the extracts were determined with an atomic absorption spectrophotometer (Hitachi Z-2000, Japan).

\subsection{Statistical analysis}

The data were analyzed as a split-plot design with irrigation method (i.e., FI or PFM-DI) as the main plot treatment and position within the profile (i.e., bulk soil or rhizosphere soil) as the sub-plot treatment. Two-factor analysis of variance was performed with SAS v8 for Windows (SAS Institute Inc., USA) to test for differences in nutrient concentration between irrigation methods and between locations within the profile. Means were separated using Duncan's multiple range test.

\section{Results}

\subsection{Soil mineral $N$}

Soil $\mathrm{NH}_{4}-\mathrm{N}$ concentrations were significantly higher in the FI treatment than in the PFM-DI treatment on all sampling dates $(p<0.01$, Table 1$)$. In contrast, NO3-N concentrations were significantly lower in the FI treatment than in the PFM-DI treatment $(p<0.01$, Table 2). Mineral $\mathrm{N}$ concentrations in the bulk soil were significantly different from those in the rhizosphere soil (Table 1 and 2). Specifically, $\mathrm{NH}_{4}-\mathrm{N}$ concentrations were much lower in rhizosphere soil than in bulk soil. In contrast, $\mathrm{NO}_{3}-\mathrm{N}$ concentrations were much higher in rhizosphere soil than in bulk soil. Soil $\mathrm{NH}_{4}-\mathrm{N}$ and $\mathrm{NO}_{3}-\mathrm{N}$ concentrations both decreased as the rice grew. 
Table 1. Soil NH4-N concentrations $\left(\mathrm{mg} \mathrm{kg}^{-1}\right)$ in rhizosphere (RS) and bulk (BS) soil under conventional flood irrigation (FI) and plastic film mulch plus drip irrigation (PFM-DI).

\begin{tabular}{ccccrc}
\hline \multicolumn{2}{c}{ Treatment } & July 4 & July 29 & Aug 24 & Sept 9 \\
\hline Irrigation $^{\mathrm{a}}$ & PFM-DI & $11.3 \pm 2.1$ & $2.9 \pm 1.05$ & $2.6 \pm 0.7$ & $2.3 \pm 0.9$ \\
(Irr) & FI & $34.6 \pm 11.1$ & $18.7 \pm 18.5$ & $10.37 \pm 5.7$ & $5.4 \pm 2.6$ \\
Position $^{\mathrm{b}}$ & BS & $23.4 \pm 18.7$ & $19.7 \pm 23.8$ & $9.2 \pm 7.7$ & $6.2 \pm 2.7$ \\
(Pos) $^{\text {Pos }}$ & RS & $19.5 \pm 7.40$ & $5.9 \pm 2.9$ & $4.8 \pm 2.1$ & $2.6 \pm 1.1$ \\
& & & F values \\
& Irr & $127.0^{* *}$ & $239.4^{* *}$ & $72.2^{* *}$ & $51.7^{* *}$ \\
& Pos & $12.8^{*}$ & $238.4^{* *}$ & $21.6^{* *}$ & $50.6^{* *}$
\end{tabular}

a Values are the means of both BS and RS samples \pm SD. b Values are the means of both PFM-DI and FI treatments \pm SD. Asterisks indicate significant differences at $p<0.05(*)$ and $p<0.01(* *)$ according to the F-tests.

Table 2. Soil $\mathrm{NO}_{3}$ concentrations (mg kg${ }^{-1}$ ) in rhizosphere (RS) and bulk (BS) soil under conventional flood irrigation (FI) and plastic film mulch plus drip irrigation (PFM-DI).

\begin{tabular}{cccccc}
\hline \multicolumn{2}{c}{ Treatment } & July 4 & July 29 & Aug 24 & Sept 9 \\
\hline Irrigation $^{\text {a }}$ & PFM-DI & $63.7 \pm 38.7$ & $155.7 \pm 135.5$ & $89.7 \pm 68.2$ & $40.0 \pm 20.1$ \\
(Irr) & FI & $8.8 \pm 3.5$ & $29.4 \pm 8.2$ & $26.1 \pm 9.1$ & $17.4 \pm 3.7$ \\
Position $^{\text {b }}$ & BS & $16.3 \pm 14.1$ & $28.9 \pm 8.2$ & $27.7 \pm 5.2$ & $21.4 \pm 2.7$ \\
(Pos) & RS & $54.2 \pm 49.2$ & $124.6 \pm 128.3$ & $79.3 \pm 68.4$ & $33.9 \pm 22.8$ \\
& & \multicolumn{4}{c}{ F values } \\
& Irr & $225.5^{* *}$ & $87.4^{* *}$ & $101.2^{* *}$ & $38.5^{* *}$ \\
& Pos & $95.8^{* *}$ & $84.7^{* *}$ & $92.1^{* *}$ & $19.5^{* *}$ \\
\hline
\end{tabular}

a Values are the means of both BS and RS samples \pm SD. b Values are the means of both PFM-DI and FI treatments \pm SD. Asterisks indicate significant differences at $p<0.05(*)$ and $p<0.01(* *)$ according to the F-tests. 
Table 3. Olsen P concentrations ( $\mathrm{mg} \mathrm{kg}^{-1}$ ) in rhizosphere (RS) and bulk (BS) soil under conventional flood irrigation (FI) and plastic film mulch plus drip irrigation (PFM-DI).

\begin{tabular}{cccccc}
\hline \multicolumn{2}{c}{ Treatment } & July 4 & July 29 & Aug 24 & Sept 9 \\
\hline Irrigation $^{\text {a }}$ & PFM-DI & $380.8 \pm 59.7$ & $304.9 \pm 105.3$ & $285.8 \pm 43.2$ & $270.2 \pm 59.7$ \\
(Irr) & FI & $241.0 \pm 36.2$ & $94.2 \pm 46.9$ & $84.5 \pm 54.3$ & $125.6 \pm 80.7$ \\
Position $^{\text {b }}$ & BS & $281.9 \pm 91.6$ & $250.1 \pm 134.6$ & $253.4 \pm 85.4$ & $257.2 \pm 61.3$ \\
(Pos) & RS & $316.7 \pm 81.9$ & $111.1 \pm 84.9$ & $147.2 \pm 114.7$ & $153.4 \pm 105.6$ \\
& & \multicolumn{4}{c}{ F values } \\
& Irr & $43.9^{* *}$ & $32.1^{* *}$ & $127.1^{* *}$ & $38.2^{* *}$ \\
& Pos & $7.1^{*}$ & $19.4^{* *}$ & $24.0^{* *}$ & $21.5^{* *}$
\end{tabular}

a Values are the means of both BS and RS samples \pm SD. b Values are the means of both PFM-DI and FI treatments \pm SD. Asterisks indicate significant differences at $p<0.05(*)$ and $p<0.01(* *)$ according to the F-tests.

Table 4. Available K concentrations ( $\mathrm{mg} \mathrm{kg}^{-1}$ ) in rhizosphere (RS) and bulk (BS) soil under conventional flood irrigation (FI) and plastic film mulch plus drip irrigation (PFM-DI).

\begin{tabular}{cccccc}
\hline \multicolumn{2}{c}{ Treatment } & July 4 & July 29 & Aug 24 & Sept 9 \\
\hline Irrigation $^{\text {a }}$ & PFM-DI & $380.8 \pm 59.7$ & $304.9 \pm 105.3$ & $285.8 \pm 43.2$ & $270.2 \pm 59.7$ \\
(Irr) & FI & $241.0 \pm 36.2$ & $94.2 \pm 46.9$ & $84.5 \pm 54.3$ & $125.6 \pm 80.7$ \\
Position $^{\text {b }}$ & BS & $281.9 \pm 91.6$ & $250.1 \pm 134.6$ & $253.4 \pm 85.4$ & $257.2 \pm 61.3$ \\
(Pos) & RS & $316.7 \pm 81.9$ & $111.1 \pm 84.9$ & $147.2 \pm 114.7$ & $153.4 \pm 105.6$ \\
& & \multicolumn{4}{c}{ F values } \\
& Irr & $43.9^{* *}$ & $32.1^{* *}$ & $127.1^{* *}$ & $38.2^{* *}$ \\
& Pos & $7.1^{*}$ & $19.4^{* *}$ & $24.0^{* *}$ & $21.5^{* *}$
\end{tabular}

a Values are the means of both BS and RS samples \pm SD. b Values are the means of both PFM-DI and FI treatments \pm SD. Asterisks indicate significant differences at $p<0.05(*)$ and $p<0.01(* *)$ according to the F-tests.

\subsection{Olsen $P$}

No significant differences in Olsen $\mathrm{P}$ concentration were observed between the FI and PFM-DI treatments (Table 3). Olsen P concentrations in bulk soil were similar to those in rhizosphere soil on most sampling dates. The exception was that on 24 August, Olson P concentrations were significantly lower in rhizosphere soil than in bulk soil. 


\subsection{Available $K$}

Available K concentrations were much higher in the PFM-DI treatment than in the FI treatment on all sampling dates (Table 4). Available K concentrations were much greater in rhizosphere soil than in bulk soil on July 4. However, on subsequent sampling dates, available $\mathrm{K}$ concentrations were greater in bulk soil than in rhizosphere soil.

Table 5. Available $\mathrm{Zn}$ concentrations $\left(\mathrm{mg} \mathrm{kg}^{-1}\right)$ in rhizosphere (RS) and bulk (BS) soil under conventional flood irrigation (FI) and plastic film mulch plus drip irrigation (PFM-DI).

\begin{tabular}{cccccc}
\hline \multicolumn{2}{c}{ Treatment } & July 4 & July 29 & Aug 24 & Sept 9 \\
\hline Irrigation $^{\mathrm{a}}$ & PFM-DI & $0.27 \pm 0.04$ & $0.67 \pm 0.18$ & $1.32 \pm 0.38$ & $0.69 \pm 0.34$ \\
(Irr) & FI & $0.39 \pm 0.12$ & $0.45 \pm 0.09$ & $1.03 \pm 0.12$ & $0.51 \pm 0.41$ \\
Position $^{\mathrm{b}}$ & BS & $0.30 \pm 0.03$ & $0.51 \pm 0.06$ & $0.94 \pm 0.05$ & $0.99 \pm 0.07$ \\
(Pos) & RS & $0.38 \pm 0.16$ & $0.63 \pm 0.23$ & $1.40 \pm 0.29$ & $0.30 \pm 0.15$ \\
& & \multicolumn{4}{c}{ F values } \\
& Irr & $32.4^{* *}$ & $21.7^{* *}$ & $30.3^{* *}$ & $34.7^{* *}$ \\
& Pos & $10.5^{*}$ & $7.2^{*}$ & $71.4^{* *}$ & $488.6^{* *}$ \\
\hline
\end{tabular}

a Values are the means of both BS and RS samples \pm SD. bValues are the means of both PFM-DI and FI treatments \pm SD. Asterisks indicate significant differences at $p<0.05(*)$ and $p<0.01(* *)$ according to the F-tests.

\subsection{Available Zn}

Available Zn concentrations in both the FI and PFM-DI treatments rose between July 4 and August 24 and then declined (Table 5). The temporal changes were similar to temporal changes in soil temperatures during the growing season. The available $\mathrm{Zn}$ concentration in the FI treatment on July 4 was significantly greater than that in the PFM-DI treatment (Table 5). In contrast, available $\mathrm{Zn}$ concentrations were significantly lower in the FI treatment than in the PFM-DI treatment on July 29, August 24, and September 7. Available Zn concentrations in rhizosphere soil were greater than those in bulk soil except for September 7.

\subsection{Exchangeable Mn and easily reduced Mn}

Exchangeable Mn concentrations were significantly greater in the FI treatment than in the PFM-DI treatment on all sampling dates (Table 6). Easily reduced $\mathrm{Mn}$ can be quickly transformed into exchangeable $\mathrm{Mn}$; therefore, we considered easily reduced Mn to be a supplementary source of available $\mathrm{Mn}$ in this study. Easily reduced Mn concentrations were significantly higher in the PFM-DI treatment than in the FI treatment on all sampling dates (Table 7). There was generally no significant difference in easily reduced $\mathrm{Mn}$ concentration between rhizosphere soil and bulk soil. 
Table 6. Exchangeable Mn concentrations ( $\mathrm{mg} \mathrm{kg}^{-1}$ ) in rhizosphere (RS) and bulk (BS) soil under conventional flood irrigation (FI) and plastic film mulch plus drip irrigation (PFM-DI).

\begin{tabular}{cccccc}
\hline \multicolumn{2}{c}{ Treatment } & July 4 & July 29 & Aug 24 & Sept 9 \\
\hline Irrigation $^{\text {a }}$ & PFM-DI & $52.9 \pm 6.9$ & $55.0 \pm 5.2$ & $38.2 \pm 3.1$ & $44.5 \pm 3.8$ \\
(Irr) & FI & $31.5 \pm 4.6$ & $13.7 \pm 2.4$ & $16.0 \pm 3.5$ & $17.0 \pm 4.4$ \\
Position $^{\text {b }}$ & BS & $39.3 \pm 9.3$ & $33.8 \pm 20.2$ & $26.7 \pm 14.0$ & $31.1 \pm 16.6$ \\
(Pos) & RS & $43.2 \pm 17.0$ & $31.8 \pm 23.1$ & $29.1 \pm 11.3$ & $32.4 \pm 14.4$ \\
& & \multicolumn{4}{c}{ F values } \\
& Irr & $45.1^{* *}$ & $497.8^{* *}$ & $155.6^{* *}$ & $130.0^{* *}$ \\
& Pos & 0.6 & 0.5 & 0.2 & 0.0 \\
\hline
\end{tabular}

a Values are the means of both BS and RS samples \pm SD. $\mathbf{b}$ Values are the means of both PFM-DI and FI treatments \pm SD. Asterisks indicate significant differences at $p<0.05(*)$ and $p<0.01(* *)$ according to the F-tests.

Table 7. Easily reduced $\mathrm{Mn}$ concentration $\left(\mathrm{mg} \mathrm{kg}^{-1}\right)$ in rhizosphere (RS) and bulk (BS) soil under conventional flood irrigation (FI) and plastic film mulch plus drip irrigation (PFM-DI).

\begin{tabular}{cccccc}
\hline \multicolumn{2}{c}{ Treatment } & July 4 & July 29 & Aug 24 & Sept 9 \\
\hline Irrigation $^{\mathrm{a}}$ & PFM-DI & $52.9 \pm 6.9$ & $55.0 \pm 5.2$ & $38.2 \pm 3.1$ & $44.5 \pm 3.8$ \\
(Irr) & FI & $31.5 \pm 4.6$ & $13.7 \pm 2.4$ & $16.0 \pm 3.5$ & $17.0 \pm 4.4$ \\
Position $^{\mathrm{b}}$ & BS & $39.3 \pm 9.3$ & $33.8 \pm 20.2$ & $26.7 \pm 14.0$ & $31.1 \pm 16.6$ \\
(Pos) & RS & $43.2 \pm 17.0$ & $31.8 \pm 23.1$ & $29.1 \pm 11.3$ & $32.4 \pm 14.4$ \\
& & & \multicolumn{2}{c}{ F values } \\
& Irr & $45.1^{* *}$ & $497.8^{* *}$ & $155.6^{* *}$ & $130.0^{* *}$ \\
& Pos & 0.6 & 0.5 & 0.2 & 0.0
\end{tabular}

a Values are the means of both BS and RS samples \pm SD. b Values are the means of both PFM-DI and FI treatments \pm SD. Asterisks indicate significant differences at $p<0.05(*)$ and $p<0.01(* *)$ according to the F-tests. 


\section{Discussion}

\subsection{Nutrient availability}

Plants can take up $\mathrm{N}$ in the form of either $\mathrm{NH}_{4}$ or $\mathrm{NO}_{3}$. In this paper, $\mathrm{NO}_{3}-\mathrm{N}$ concentrations were much greater in the PFM-DI treatment than in the FI treatment. This is because the oxygen content and the redox potential of soil were higher in the PFM-DI treatment than in the FI treatment. In contrast, $\mathrm{NH}_{4}-\mathrm{N}$ concentrations were much greater in the FI treatment than in the PFM-DI treatment. This indicates that the soil environment under PFM-DI promoted nitrification. These observations were similar to those by Roelcke (2002) and Cai et al (2002). Total inorganic N concentrations $\left(\mathrm{NH}_{4}+\mathrm{NO}_{3}\right)$ were greater in the PFM-DI treatment than in the FI treatment at all growth stages, indicating that the ability of the soil to supply $\mathrm{N}$ to the rice crop was greater in the PFM-DI system than in the FI system. This explains the observation that rice yields were higher in the PFM-DI system than in the FI system (Guo and Chen 2012).

There was no significant difference in Olsen $\mathrm{P}$ concentration between the FI and PFM-DI treatments. A previous study indicated that flood irrigation caused soil $\mathrm{pH}$ to shift towards neutral, resulting in an increase in available $\mathrm{P}$ (Rubio, 1997). Based on this finding, we expected available $\mathrm{P}$ concentrations to be higher in the FI treatment than in the PFM-DI treatment. We cannot explain our unexpected result at the present time.

Available K concentrations were significantly higher in the PFM-DI treatment than in the FI treatment. One explanation is that available $\mathrm{K}$ may have leached from the soil in the FI treatment. Previous reports indicated that flood irrigation leached available $\mathrm{K}$ from sandy soil with high $\mathrm{K}$ concentrations (Askegaard and Eriksen 2000).

Soil exchangeable Mn concentrations were significantly less in the PFM-DI treatment than in the FI treatment. In contrast, easily reduced Mn concentrations in the PFM-DI treatment were significantly greater than those in the FI treatment. This indicated that aerobic conditions and the high redox potential of soil in the PFM-DI treatment resulted in oxidation of exchangeable $\mathrm{Mn}$ to form easily reduced Mn. These results are consistent with observations by Patrick and Jugsujinda (1992). Soil exchangeable Mn was greater than the critical value $(5 \mathrm{mg} / \mathrm{kg})$ in both the FI and the PFM-DI treatments. This means that Mn concentrations were high enough to meet the demands of the growing rice plants (Nayyar et al., 1985). On the other hand, the concentration of exchangeable Mn in the PFM-DI treatment was low enough to reduce or eliminate the possibility of Mn toxicity (Nayyar et al., 1985).

Soil $\mathrm{Zn}$ availability in the FI treatment was greater than that in the PFM-DI treatment on the first three sampling dates, but less than that in the PFM-DI treatment on the last sampling date. One explanation is that soil $\mathrm{pH}$ tends to be neutral in water-logged soil (Larson et al. 1991). Under this condition, $\mathrm{H}_{2} \mathrm{~S}$ could react with $\mathrm{Zn}$ to form $\mathrm{ZnS}$ which would then precipitate out of the soil solution. This would decrease $\mathrm{Zn}$ availability (Johnson-Beebout et al. 2009).

In summary, a shift from FI to PFM-DI would lead to increases in plant available N, K, and Zn. Exchangeable Mn would decrease in the PFM-DI system, whereas $P$ availability would remain nearly the same.

\subsection{Bulk soil versus rhizosphere soil}

Soil $\mathrm{NH}_{4}-\mathrm{N}$ concentrations were lower, whereas $\mathrm{NO}_{3}-\mathrm{N}$ concentrations were higher, in rhizosphere soil than in bulk soil. Several factors may contribute to this phenomenon. First, rice may have preferentially absorbed $\mathrm{NH}_{4}-\mathrm{N}$, resulting in a decrease in soil $\mathrm{pH}$ in rhizosphere soil (Kronzucker et al. 1998). b). Secondly, $\mathrm{NH}_{4}^{+}$is strongly adsorbed by negatively charged soil colloids, thus reducing $\mathrm{NH}_{4}-\mathrm{N}$ movement in soil (Herrmann et al. 2005). If plants took up $\mathrm{NH}_{4}-\mathrm{N}$ from rhizosphere soil faster than the $\mathrm{NH}_{4}-\mathrm{N}$ could be replenished from bulk soil, then $\mathrm{NH}_{4}-\mathrm{N}$ concentrations would decline. Thirdly, aerenchyma around rice roots 
create an oxidizing microenvironment that favors the transformation of $\mathrm{NH}_{4}$ into $\mathrm{NO}_{3}$ (Begg et al. 2006). This could also explain the increase in $\mathrm{NO}_{3}-\mathrm{N}$ that we observed in rhizosphere soil in the PFM-DI treatment. Nitrate- $\mathrm{N}$ is very mobile in soil. Therefore, $\mathrm{NO}_{3}-\mathrm{N}$ could be carried from bulk soil to rhizosphere soil as plants take up and transpire water (Herrmann et al. 2005).

Available $\mathrm{K}$ concentrations were depleted in rhizosphere soil. In contrast, there was no difference in Olsen $\mathrm{P}$ concentration between bulk soil and rhizosphere soil. One explanation is that a huge pool of available $\mathrm{P}$ in bulk soil may have buffered available $\mathrm{P}$ concentrations against declines that would have occurred due to plant uptake from rhizosphere soil (Willett 1978). Another possibility is that the $\mathrm{pH}$ of rhizosphere soil declined as plants selectively absorbed $\mathrm{NH}_{4}^{+}$. This decrease in soil $\mathrm{pH}$ could cause an increase in available P concentrations (Gahoonia and Nielsen 1992; Marschner and Römheld 1983).

Available $\mathrm{Zn}$ concentrations were generally higher in rhizosphere soil than in bulk soil. Zinc is an immobile nutrient ( $\mathrm{Lu}$ 2003). Therefore, it is not likely that the movement of $\mathrm{Zn}$ from bulk soil to rhizosphere soil can account for increased available $\mathrm{Zn}$ concentrations in rhizosphere soil. It is more likely that the availability of $\mathrm{Zn}$ in rhizosphere soil increased due to a decline in the $\mathrm{pH}$ of rhizosphere soil that occurred as rice absorbed $\mathrm{NH}_{4}$ (Marschner and Römheld 1983).

Exchangeable Mn concentrations were higher in rhizosphere soil than in bulk soil during the early part of the growing season. One explanation is that exchangeable Mn was transported from bulk soil to rhizosphere soil as plants took up water. A previous report indicated that the mobility of Mn increased after waterlogging ( $\mathrm{Lu}$ et al. 2004).

In summary, differences in nutrient content between rhizosphere soil and bulk soil mainly depend on nutrient mobility and on selective absorption by the plants. The buffering capacity of the soil also plays an important role.

\section{Conclusion}

The following conclusions can be drawn from our study. Overall, a shift from FI to PFM-DI favors the conversion of $\mathrm{NH}_{4}$ to $\mathrm{NO}_{3}$ via nitrification. The availability of $\mathrm{K}$ and $\mathrm{Zn}$ both increased in the PFM-DI system, whereas the availability of $\mathrm{Mn}$ decreased. The latter effect reduces the likelihood of Mn toxicity to plants. The shift from FI to PFM-DI had negligible effect on available $\mathrm{P}$ concentrations. Nutrient availability varied depending on position within the soil profile. . The concentrations of $\mathrm{NO}_{3}-\mathrm{N}$ and available $\mathrm{Zn}$ were greater in rhizosphere soil than in bulk soil. In contrast, neither easily reduced Mn concentration nor available P concentration were affected by position in the soil profile.

\section{Acknowledgements}

This study was supported by the National High Technology Research and Development Program of China (2011AA100508), and by the Bingtuan Fund for Distinguished Young Scientists (2011CD004). The authors would like to thank Dr. William Gale for help with the English in this manuscript.

\section{References}

Askegaard, M, Eriksen, J. 2000. Potassium retention and leaching in an organic crop rotation on loamy sand as affected by contrasting potassium budgets. Soil Use and Management. 16, 200205.

Begg, C.B.M., Kirk, G.J.D., Mackenzie, A.F., Neue, H.-U. 2006. Root-induced iron oxidation and $\mathrm{pH}$ changes in the lowland rice rhizosphere. New Phytologist. 128, 469-477.

Cai, Z.C. 2002. Ammonium transformation in paddy soils affected by the presence of nitrate. Nutrient Cycling in Agroecosystems. 63, 267-274. 
Ciarlo, E., Conti, M., Bartoloni, N., Rubio, G. 2007. The effect of moisture on nitrous oxide emissions from soil and the $\mathrm{N}_{2} \mathrm{O} /\left(\mathrm{N}_{2} \mathrm{O}+\mathrm{N}_{2}\right)$ ratio under laboratory conditions. Biology and Fertility of Soils. 43, 675-681.

Dorich, R.A., Nelson, D.W. 1983. Direct colorimetric measurement of ammonium in potassium chloride extracts of soils. Soil Science Society of America Journal. 47, 833-836.

Dorich, R.A., Nelson, D,W. 1984. Evaluation of manual cadmium reduction methods for determination of nitrate in potassium chloride extracts of soils. Soil Science Society of America Journal. 48, 72-75.

Gahoonia, T.S., Nielsen, N.E. 1992. The effects of root-induced $\mathrm{pH}$ changes on the depletion of inorganic and organic phosphorus in the rhizosphere. Plant and Soil. 143, 185-191.

Guo Q.R., Chen L. 2012. Analysis of advantage and prospects for rice drip irrigation under plastic film cultivation development in China. China Rice. 18, 36-39.

Herrmann, M., Pust, J., Pott, R. 2005. Leaching of nitrate and ammonium in heathland and forest ecosystems in Northwest Germany under the influence of enhanced nitrogen deposition. Plant and Soil. 273, 129-137.

Johnson-Beebout, S.E., Lauren, J.G., Duxbury, J.M. 2009. Immobilization of zinc fertilizer in flooded soils monitored by adapted DTPA soil test. Communications in Soil Science and Plant Analysis. 40, 1842-1861.

Kronzucker, H.J., Kirk, G.J.D., Siddiqi, M.Y., Glass, A.D.M. 1998. Effects of hypoxia on ${ }^{13} \mathrm{NH}_{4+}$ fluxes in rice roots. Plant physiology. 116, 581-587.

Larson, K.D., Graetz, D.A., Schaffer, B. 1991. Floodinduced chemical transformations in calcareous agricultural soils of south Florida. Soil Science, 152: (1), 33-40.

Lindsay, W.L., Norvell, W.A. 1978. Development of a DTPA soil test for zinc, iron, manganese, and copper. Soil Science Society of America Journal. 42, 421-428.

Lu, J.L. 2003. Plant Nutrition v.1. China Agricultural University press, Beijing,136-155.

Lu, S.H, Liu, X.J., Li, L., Zhang, F.S., Zeng, X.Z., Tang, C.X. 2004. Effect of manganese spatial distribution in the soil profile on wheat growth in rice-wheat rotation. Plant and Soil. 261, 39-46.

Marschner, H., Römheld, V. 1983. In vivo measurement of root-induced $\mathrm{pH}$ changes at the soil-root interface: effect of plant species and nitrogen source. Zeitschrift für Pflanzenphysiologie. 111, 241-251.

Martínez-Alcalá, I., Clemente, R., Bernal, M.P. 2009. Metal availability and chemical properties in the rhizosphere of Lupinus albus L. growing in a high-metal calcareous soil. Water, Air, and Soil Pollution. 201, 283-293.

Moraghan, J.T. 1979. Manganese toxicity in flax growing on certain calcareous soils low in available iron. Soil Science Society of America Journal. 43, 1177-1180.

Nayyar V.K., U.S. Sadana, T.N. Takkar. 1985. Methods and rates of application of $\mathrm{Mn}$ and its critical levels for wheat following rice on coarse textured soils, Fertilizer Research 8(2): 173-178.

Oliveira, V., Ludwick, A.E., Beatty, M.T. 1971. Potassium removed from some Southern Brazilian soils by exhaustive cropping and chemical extraction methods. Soil Science Society of America Journal. 35, 763-767. 
Patrick, W.H., Jugsujinda, A. 1992. Sequential reduction and oxidation of inorganic nitrogen, manganese, and iron in flooded soil. Soil Science Society of America Journal. 56, 1071-1073.

Roelcke, M., Han, Y., Cai, Z.C., Richter, J. 2002. Nitrogen mineralization in paddy soils of the Chinese Taihu Region under aerobic conditions. Nutrient Cycling in Agroecosystems. 63, 255-266.

Rubio, G., Oesterheld, M., Alvarez, C.R., Lavado, R.S. 1997. Mechanisms for the increase in phosphorus uptake of waterlogged plants: soil phosphorus availability, root morphology and uptake kinetics. Oecologia. 112, 150-155.

Wang, Z., Shan, X., Zhang, S. 2002. Comparison between fractionation and bioavailability of trace elements in rhizosphere and bulk soils. Chemosphere. 46, 1163-1171.
Watanabe, F.S., Olsen, S.R.. 1965. Test of an ascorbic acid method for determining phosphorus in water and $\mathrm{NaHCO}_{3}$ extracts from soil. Soil Science Society of America Journal. 29, 677-678.

Willett, I.R., Higgins, M.L. 1978. Phosphate sorption by reduced and reoxidized rice soils. Soil Research. 16, 319-326.

Yoneyama, T., Matsumaru, T., Usui, K., Engelaar, W. 2001. Discrimination of nitrogen isotopes during absorption of ammonium and nitrate at different nitrogen concentrations by rice (Oryza sativa L.) plants. Plant, Cell \& Environment. 24, 133-139. 